\title{
ELECTROREFINING OF HIGH CARBON FERROMANGANESE IN MOLTEN SALTS TO PRODUCE PURE FERROMANGANESE
}

\begin{abstract}
High carbon ferromanganese is used as a starting material to prepare pure ferromanganese by electrorefining in molten salts. High carbon ferromanganese was applied as the anode, molybdenum was the cathode and $\mathrm{Ag} / \mathrm{AgCl}$ was the reference electrode. The anodic dissolution was investigated by linear polarization in molten $\mathrm{NaCl}-\mathrm{KCl}$ system. Then potentiostatic electrolysis was carried out to produce pure ferromanganese from high carbon ferromanganese. The cathodic product was determined to be a mixture of manganese and iron by x-ray diffraction (XRD). The content of carbon in the product was analyzed by carbon and sulfur analyzer. The post-electrolysis anode was characterized by scanning electron microscope (SEM). The mechanism of the anode dissolution and the distribution of the main impurity of carbon and silicon after electrolysis were discussed.

Keywords: high carbon ferromanganese, electrorefining, molten salts, pure ferromanganese
\end{abstract}

\section{Introduction}

High-Mn (10-30 wt \% ) TWIP (twinning induced plasticity) steel is being developed as the third-generation one for cars [1]. The resource for manganese alloying agent in this type of steel is from electrolytic manganese, which is expensive due to a low current efficiency and high cell voltage for the corresponding electrolytic cell, and the shortage of the raw material $\mathrm{MnCO}_{3}$ ore for electrolytic manganese, also caused cost increase [2,3]. Therefore, it is necessary to provide cheap and high-purity manganese or ferromanganese for the development of TWIP steel. The investigation of producing low-cost and pure ferromanganese has been carried out by Norwegian University of Science and Technology [4] and the TU Clausthal in Germany and Siemens VAI Technology Co., Ltd. [5], which is still at the laboratory scale. High-carbon ferromanganese is a type of attractive candidate for preparing low-cost and pure ferromanganese. Cheap high-carbon ferromanganese could be used as the anode in an electrorefining cell to produce pure ferromanganese at the cathode. The electrorefining could be carried out in aqueous solution or molten salts. The current electrolytic process is performed in aqueous solution, which produce large amount of waste water and residue containing ammonia, causing serious environmental pollution. The addition of ammonia sulfate to the solution is to stabilize the Mn ions and enhance the conductivity of the electrolyte [6]. Therefore, it could be better to select molten salts as the electrolyte for the electrorefining of high carbon ferromanganese. Actually $\mathrm{Mn}-\mathrm{Al}$ alloy and pure $\mathrm{Mn}$ have been prepared in molten salts in previous studies [7,8]. Molten salts electrorefining is clean, with high conductivity, high current density and high productivity. Thus the electrorefining of high carbon ferromanganese in molten salts to prepare pure ferromanganese is considered to be an attractive method and was investigated in this paper. In 1969 premium chromium was obtained from highcarbon ferrochromium by molten salts electrorefining, followed by magnetic separation by US Bureau of Mines [9]. In 1971 pure vanadium was electrochemically prepared from $\mathrm{V}_{2} \mathrm{C}$ in molten chlorides system by the same group [10].

In this paper high carbon ferromanganese was used as the anode, dissolved in the electrolyte, with manganese ions and iron ions migrating to the cathode and discharging at the cathode, to produce pure ferromanganese.

\section{Experimental}

$\mathrm{NaCl}$ and $\mathrm{KCl}$ (Sinopharm Chemical Reagent Co., Ltd, AR) with a molar ratio (1:1) were chosen as the electrolyte with the operating temperature at $983 \mathrm{~K}\left(710^{\circ} \mathrm{C}\right)$. They were dried under atmosphere at $473 \mathrm{~K}\left(200^{\circ} \mathrm{C}\right)$ for at least $48 \mathrm{~h}$ prior to be used as the electrolyte. High carbon ferromanganese $(65.6 \mathrm{wt} \%$ Mn; $26.1 \mathrm{wt} \%$ Fe; $6.1 \mathrm{wt} \%$ C; Maanshan City Shun ferroalloy Trading Co. Ltd) was used as the starting material. In the test of cyclic voltammetry (CV), high carbon ferromanganese and high-purity carbon ( $\Phi 5 \mathrm{~mm}$, Zibo Jinpeng Carbon Co., Ltd.) were used as the working electrodes, and carbon ( $\Phi 8 \mathrm{~mm}$, Zibo

\footnotetext{
SCHOOL OF METALLURGY ENGINEERING, ANHUI UNIVERSITY OF TECHNOLOGY, MAANSHAN 243032, CHINA

Corresponding author: zhangjunxiaohu@yahoo.com
} 
Jinpeng Carbon Co., Ltd.) as the counter electrode. In the test of electrolysis, high carbon ferromanganese was used as the anode, and molybdenum ( $\Phi 1 \mathrm{~mm}$, Luoyang Kewei Molybdenum \& Tungsten Co., Ltd., 99.95\%) was selected as the cathode. The reference electrode was $\mathrm{Ag} / \mathrm{AgCl}$ with $4 \mathrm{~mol} \% \mathrm{AgCl}$ in molten $\mathrm{NaCl}-\mathrm{KCl}$ inside a mullite tube, and a silver wire was served as the lead. All the potentials in molten chlorides were referred to $\mathrm{Ag} / \mathrm{AgCl}$ reference electrode. The three-electrode cell was electrochemically tested under argon atmosphere.

The staring and post-electrolysis high carbon ferromanganese were polished, washed in ethanol and dried before analyzed by scanning electron microscope (SEM).

The electrochemical measurements were performed by PARSTAT 2273 potentiostat with Powersuite software (Princeton Applied Research, AMETEK). The product was analyzed by X-ray diffraction (XRD) (Bruker D8 Advance; Bruker corporation, Germany) using $\mathrm{Cu} \mathrm{K} \alpha$ radiation at $40 \mathrm{kV}$ and 40 $\mathrm{mA}$. The microstructure and micro-zone chemical analysis of samples were also measured using scanning electron microscope (SEM) and energy dispersive spectrometer (EDS) (JSM-6510LV; JEOL).

\section{Results and discussion}

\section{A. The anodic dissolution of high carbon ferromanganese}

Figure 1 shows the comparison of polarization curve of carbon and high carbon ferromanganese as the working electrodes in $\mathrm{NaCl}-\mathrm{KCl}$ melt at $983 \mathrm{~K}\left(710^{\circ} \mathrm{C}\right)$ by linear sweeping. The dotted line corresponds to carbon electrode and the solid line corresponds to high carbon ferromanganese. Potential sweep starts from around $-0.75 \mathrm{~V}$ and ends at $1.3 \mathrm{~V}$. From the dotted line, there is no current before $1 \mathrm{~V}$. At more positive potentials, the current appears and increases corresponding to the evolution of chlorine. While using the high carbon ferromanganese as the working electrode, from the start, the current increases slowly and from $0.1 \mathrm{~V}$, the current increased more sharply. Obviously



Fig. 1. Comparison of polarization curve of the high carbon ferromanganese and carbon in $\mathrm{NaCl}-\mathrm{KCl}$ melt at $983 \mathrm{~K}\left(710^{\circ} \mathrm{C}\right)$; scan rate: $0.1 \mathrm{~V} \mathrm{~s}^{-1}$ they correspond to the dissolution of high carbon ferromanganese. In the subsequent potentiostatic electrolysis, the anode potential was set as $0.3 \mathrm{~V}$ vs $\mathrm{Ag} / \mathrm{AgCl}$ reference electrode.

Then high carbon ferromanganese was served as the working electrode (i.e., anode), and molybdenum was used as the counter electrode (i.e., cathode). The potentiotatic electrolysis was performed, with the current-time curve shown in Figure 2, which lasted for $3 \mathrm{~h}$. It shows that from the start the current decreases with the time, and stabilizes after $2 \mathrm{~h}$. The stable anodic and cathodic current densities are around 0.15 and $1 \mathrm{~A} \mathrm{~cm}^{-2}$, respectively, and the anode potential is maintained at $0.3 \mathrm{~V}$ vs $\mathrm{Ag} / \mathrm{AgCl}$ reference electrode.

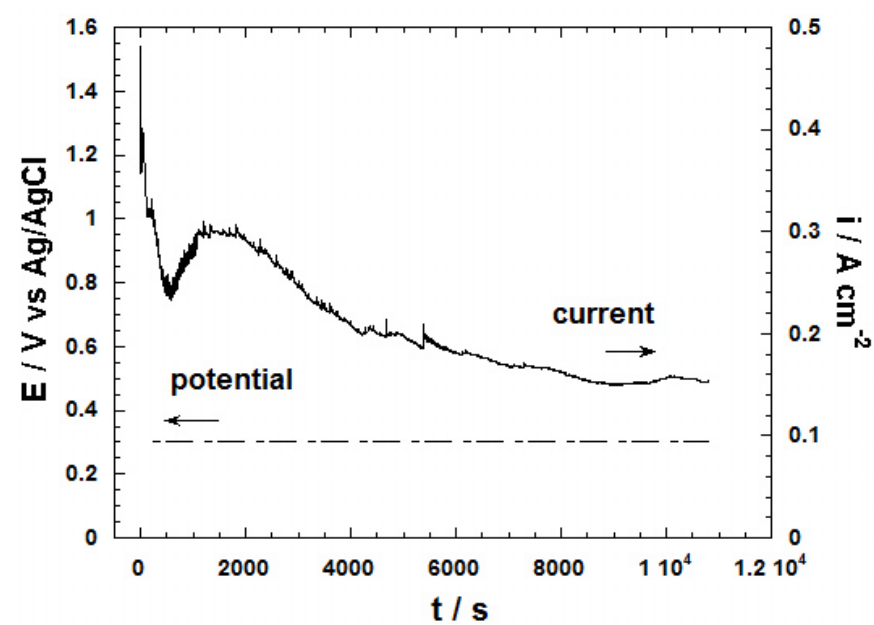

Fig. 2. Current-time curve for the dissolution of high carbon ferromanganese in $\mathrm{NaCl}-\mathrm{KCl}$ melt at $983 \mathrm{~K}\left(710^{\circ} \mathrm{C}\right)$ during potentiostatic electrolysis

\section{B. Characterization of cathode product}

After the electrolysis it was observed that part of the cathode product attached on the molybdenum cathode and part of it dropped into the melt. Both of them were recovered from the cell. Figure 3(a) presents the photos of molybdenum wire before and after the electrolysis. It is obviously observed that part of cathode product was deposited on the molybdenum wire. Then the product was washed with water to remove the salt and dried. Figure 3(b) shows the washed product, which is fine brown powder.

The powder was characterized by scanning electron microscope, shown in Figure 4(a). The powder is agglomerated and the average particle size is probably less than $1 \mu \mathrm{m}$. From the energy dispersive spectrometer, the existence of manganese, iron and oxygen were detected. The powder was also analyzed by X-ray diffraction, with the pattern shown in Figure 4(b). The observed peaks are identified as alpha $\mathrm{Mn}$, minor alpha $\mathrm{Fe}$ and $\mathrm{Mn}_{3} \mathrm{O}_{4}$. The existence of $\mathrm{Mn}_{3} \mathrm{O}_{4}$ is probably due to the contact with water and air of cathode product during its processing after the electrolysis.

The amount of the anode consumption and the recovered cathode deposit were weighed. The anode and cathode current efficiencies are estimated to be $93.5 \%$ and $79 \%$, respectively, 


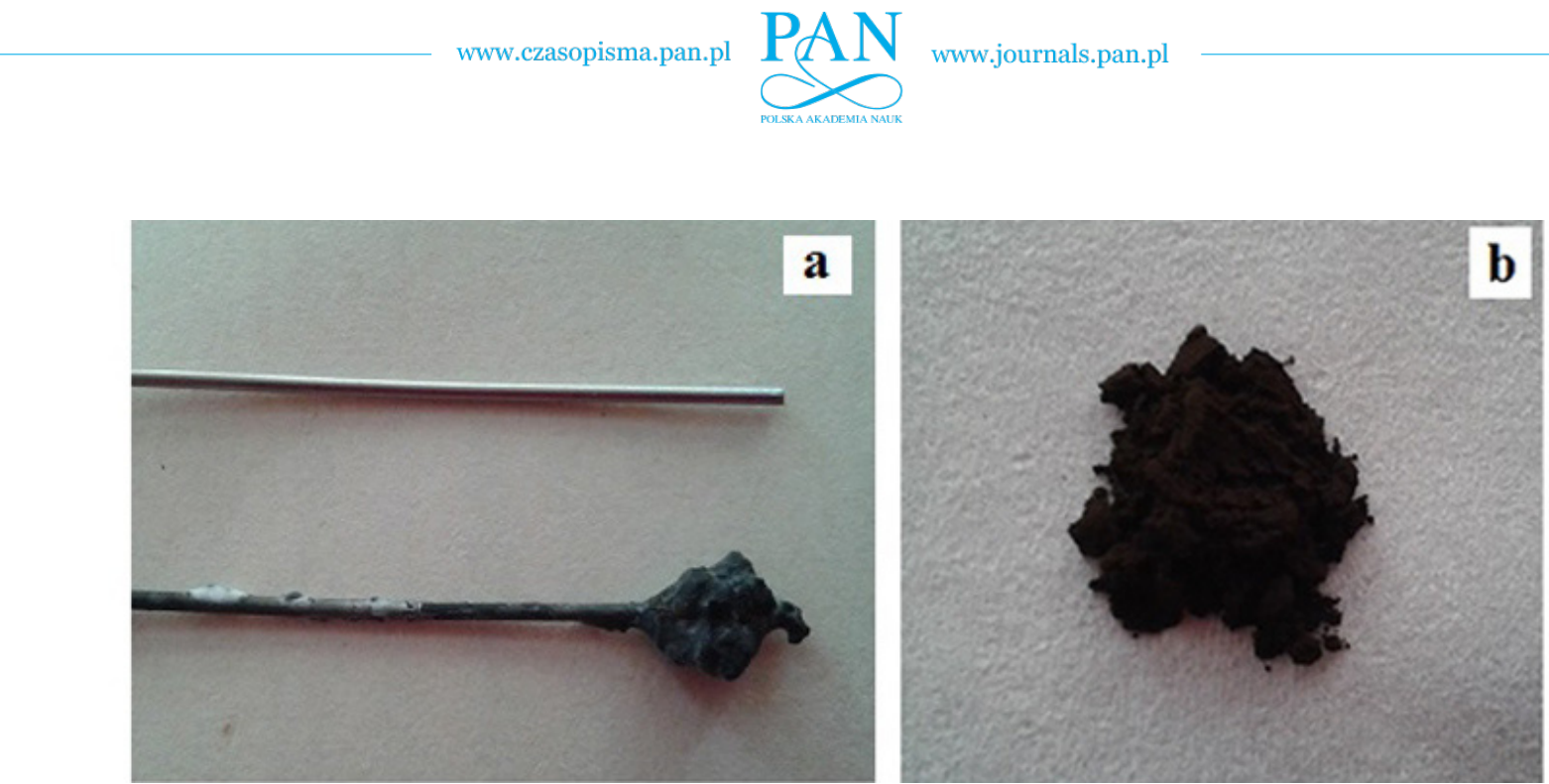

Fig. 3. Photos of molybdenum cathode before and after the electrolysis (a) and cathode product after washed and dried (b)
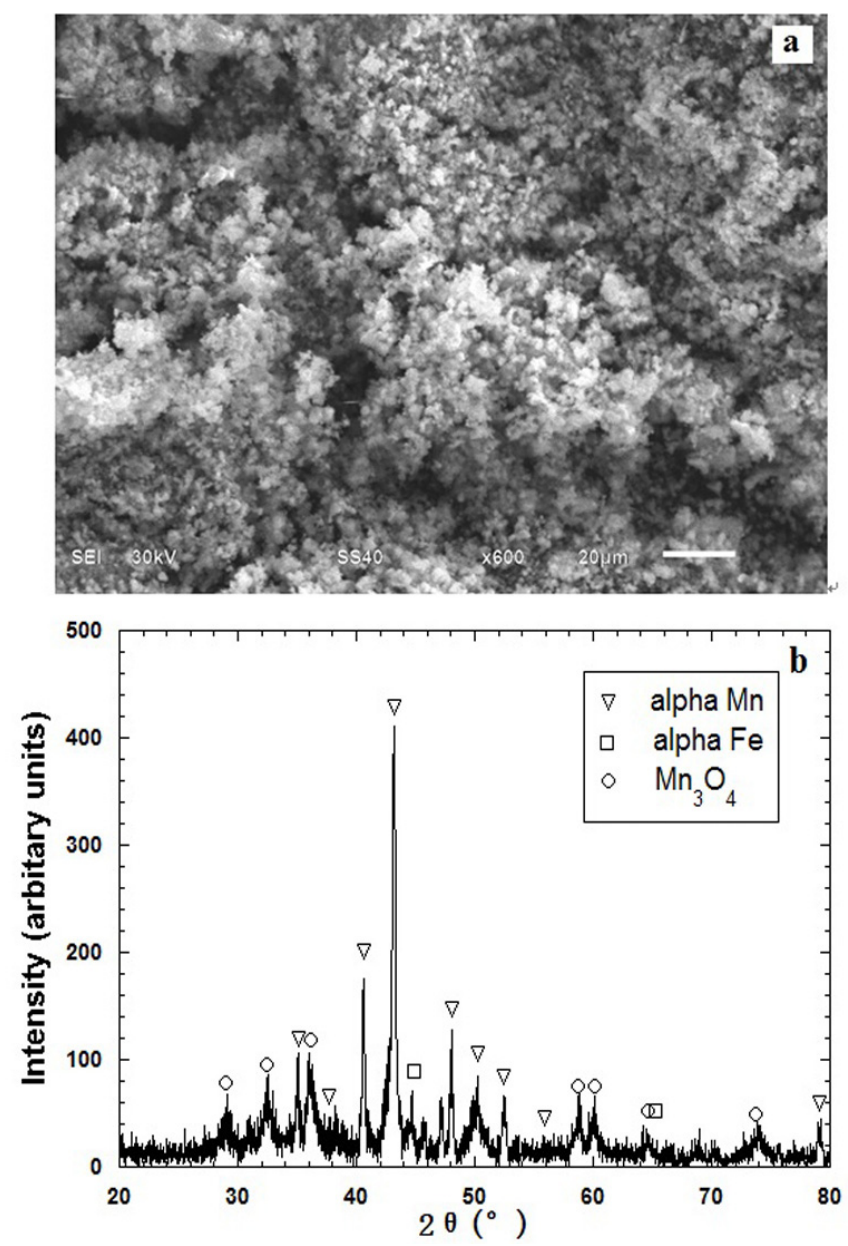

Fig. 4. Manganese metal deposited on the cathode after $3 \mathrm{~h}$ electrolysis in $\mathrm{NaCl}-\mathrm{KCl}$ melt at $983 \mathrm{~K}\left(710^{\circ} \mathrm{C}\right)$ : (a) scanning electron microscope (SEM) image of the product powder (b) X-ray diffraction pattern of the product manganese

assuming that manganese was dissolved as $\mathrm{Mn}^{2+}$ into the electrolyte (assuming manganese dissolution as the whole anode dissolution due to its similar atomic weight to iron). It was observed that the produced cathode deposit was mixed with the electrolyte. The size of the washed product is very small, which tends to be lost during the recovery steps, which is considered to cause the main loss of the cathode current efficiency.
The carbon content of the obtained ferromanganese was measured as $0.59 \mathrm{wt} \%$, a decrease by one order of magnitude compared with the starting material $(6.1 \mathrm{wt} \%)$. The carbon content of the product also meets the requirement of GB (Chinese standard) for low carbon ferromanganese. The carbon contained in the cathodic product is assumed to be from the small amount of anode mud, which fell off from the remained carbon in the anode since the cathodic product also existed in the molten salts.

\section{Analysis of post-electrolysis anode and the dissolution mechanism of anode}

After electrolysis the anode was analyzed. Figure 5 shows the photos of anode before and after electrolysis. After electrolysis the geometrical dimension is unchangeable, but the weight is reduced and the appearance has changed. On the side wall the anode loses metallic appearance. In Figure 5(b) from the bottom, there are three layers A, B and C. The outside layer (A) also lose metallic appearance, but the inside layers $\mathrm{B}$ and $\mathrm{C}$ is still metallic. So the anode is not completely dissolved. It seems that during the electrorefining, although the anode was consumed, the dimension still kept stable. It is assumed that the main remained impurities of carbon and silicon served as a body to maintain the dimension of the anode, although the main components of manganese and iron were anodically dissolved.

The mechanism of dissolution of anode was investigated. The original anode was polished and analyzed by SEM, with the image shown in Figure 6. Two phases exists in the high carbon ferromanganese. The bright grey and the dark grey phases are determined as $\mathrm{Mn}-\mathrm{Fe}-\mathrm{Si}(\sim 4 \mathrm{wt} \% \mathrm{Si})$ and $\mathrm{Mn}-\mathrm{Fe}$ by EDS, respectively. Based on previous investigation, for high carbon ferromanganese, there exists two phases: $\mathrm{Mn}-\mathrm{Fe}-\mathrm{Si}$ and $(\mathrm{MnFe})_{7} \mathrm{C}_{3}$ [11]. So it is assumed that the dark grey phase $\mathrm{Mn}-\mathrm{Fe}$ also contains carbon since the original anode contains $\sim 6 \mathrm{wt} \%$ carbon.

After electrolysis the anode was also polished and characterized by SEM. Figure 7(a) shows three layers in the anode, 

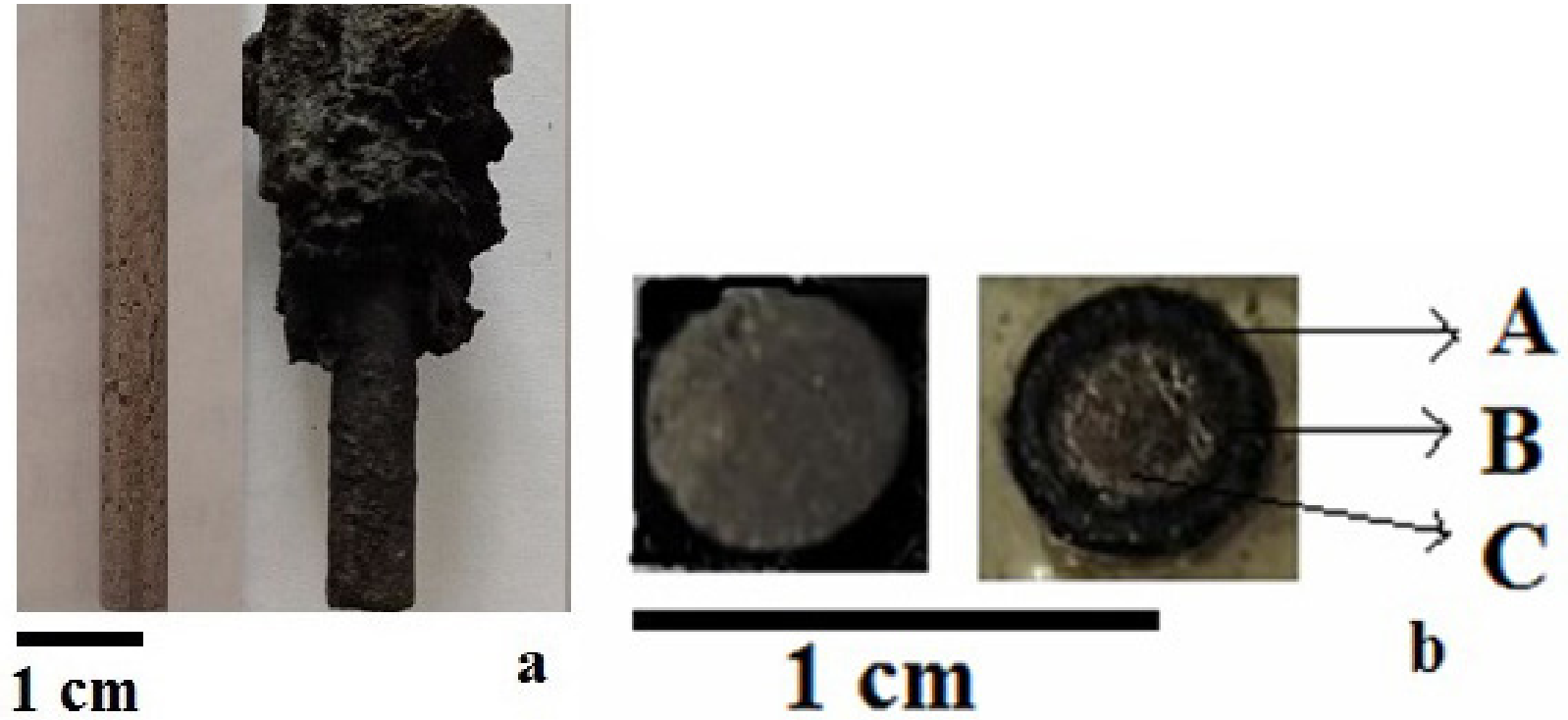

Fig. 5. Photos of anodes (a) and bottoms of anodes (b) before (left) and after (right) electrolysis

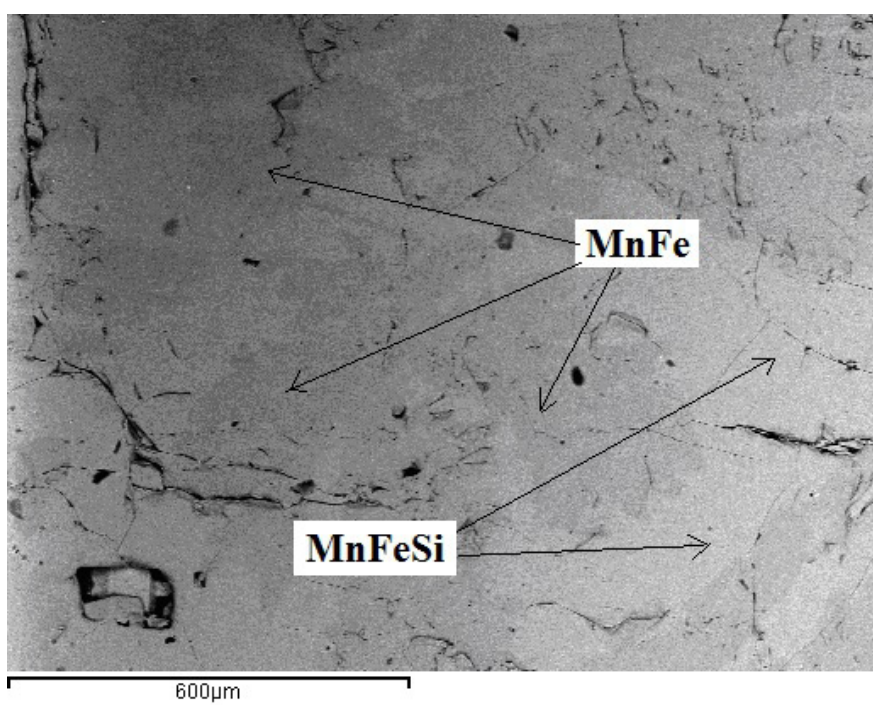

Fig. 6. SEM image and EDS analysis of starting high carbon ferromanganese

corresponding to the three layers in Figure 5(b). Figure 7(b,c) (in Figure 7(c) the sample was analyzed before polished) are the magnified SEM images of the area A (outside layer) in Figure 7(a). In Figure 7(c), carbon element could be detected by EDS when its content is close to $100 \mathrm{wt} \%$. So the outside layer (A) is mainly a mixture of silicon and carbon, where both manganese and iron were anodically dissolved. Figure 7(d) is the magnified SEM image of the layer B neighboring the outside layer A. Two phases are observed with the bright grey part corresponding mainly to $\mathrm{Fe}-\mathrm{Si}$ and dark grey part corresponding mainly to Fe, analyzed by EDS. Actually, the dark grey part should be $\mathrm{Fe}-\mathrm{C}$ phase. This indicates that manganese, contained in these two phases previously, was anodically dissolved. So part B is mixture of Fe-Si and Fe-C. Area C in Figure 7(a) corresponds to the original composition as in Figure 6. This part was not involved in the anodic dissolution.
Therefore the mechanism of anodic dissolution of manganese and iron from high carbon ferromanganese can be described as follows. For a cylinder-shaped anode of high carbon ferromanganese, firstly, in the outside layer, $\mathrm{Mn}$, contained in $\mathrm{Mn}-\mathrm{Fe}-\mathrm{Si}$ and $\mathrm{Mn}-\mathrm{Fe}-\mathrm{C}$ phases, is anodically dissolved into the electrolyte. Secondly, the remained $\mathrm{Fe}$, contained in Fe-Si and $\mathrm{Fe}-\mathrm{C}$ phases, continued to be anodically dissolved into the electrolyte. Thirdly, in the neighboring layer, $\mathrm{Mn}$, contained in $\mathrm{Mn}-\mathrm{Fe}-\mathrm{Si}$ and $\mathrm{Mn}-\mathrm{Fe}-\mathrm{C}$ phases, is anodically dissolved into the electrolyte, which is similar to the first step. Then Fe is dissolved like the second step. So it is concluded that for a cylinder-shaped anode of high carbon ferromanganese, during the electrorefining, $\mathrm{Mn}$ is dissolved into the electrolyte, followed by Fe, layer by layer.

\section{Conclusions}

High carbon ferromanganese, as the starting material, was employed as the anode during potentiostatic electrolysis in $\mathrm{NaCl}-\mathrm{KCl}$ melt at $983 \mathrm{~K}\left(710^{\circ} \mathrm{C}\right)$, with anodic and cathodic current densities as 0.15 and $1 \mathrm{~A} \mathrm{~cm}^{-2}$, respectively. Low carbon $(0.59 \mathrm{wt} \%)$ ferromanganese (a decrease of carbon content by one order magnitude compared with high carbon ferromanganese), in the form of fine brown powder, was produced. The anode and cathode current efficiencies were estimated as $93.5 \%$ and $79 \%$, respectively. During the electrorefining, the main impurity of carbon and silicon in the anode were remained at the anode, resulting in keeping a stable anode dimension; manganese dissolved followed by iron, layer by layer from a cylindric anode. $\mathrm{Mn}$ ions and $\mathrm{Fe}$ ions migrated to the cathode, with manganese and iron deposited at the cathode. This novel process provides an alternative for low-cost refining methods to produce pure ferromanganese. 


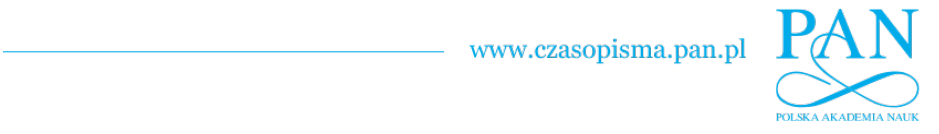

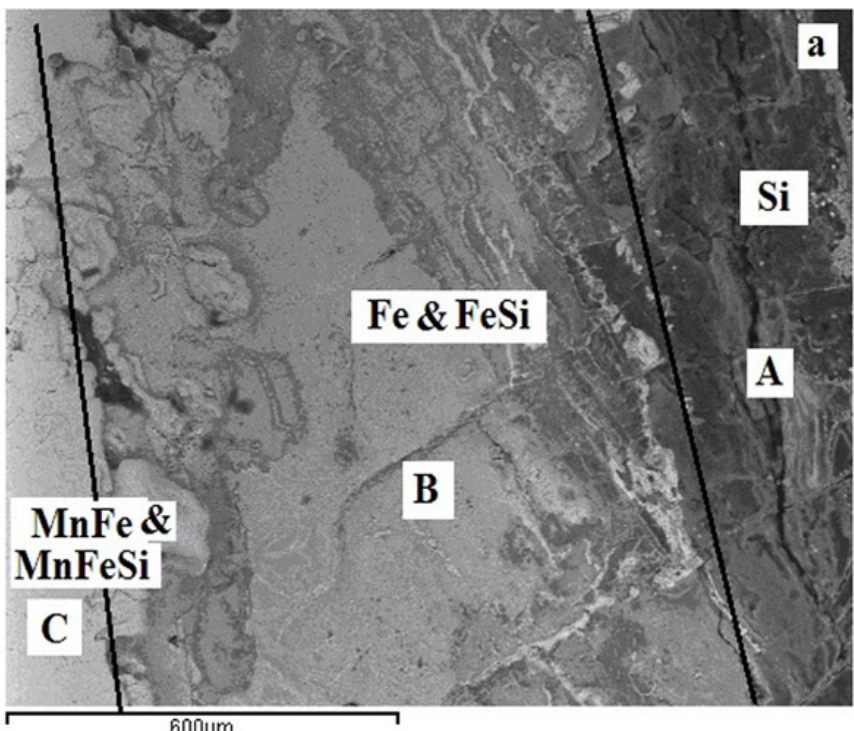

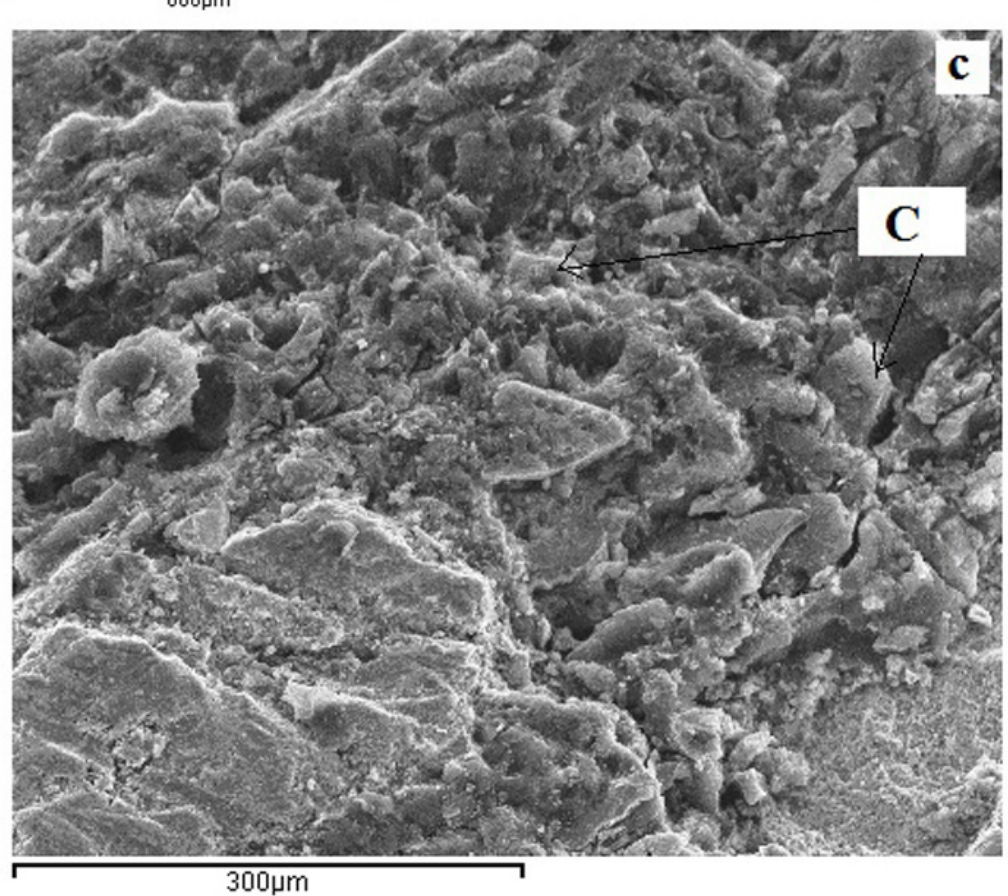

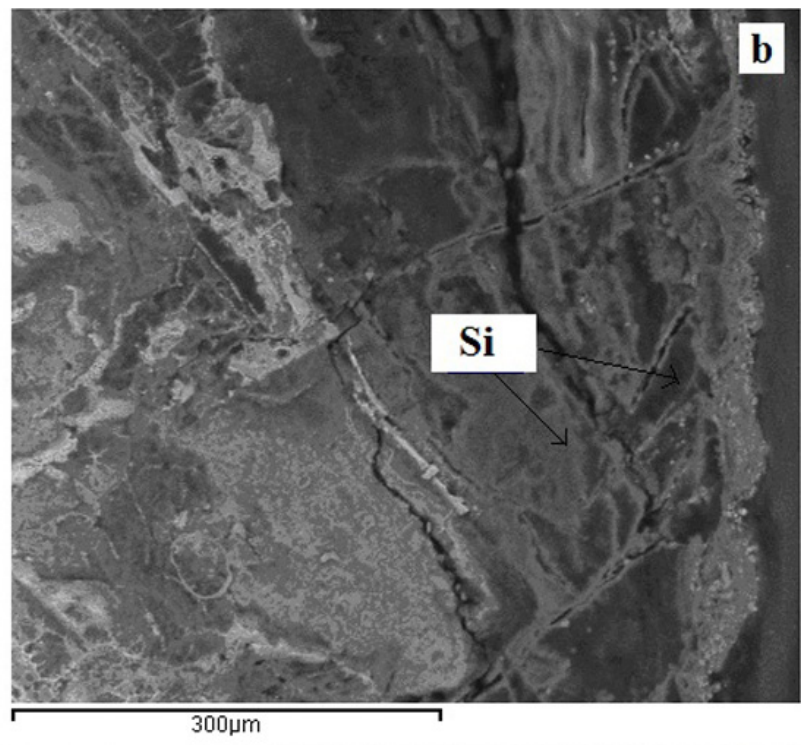

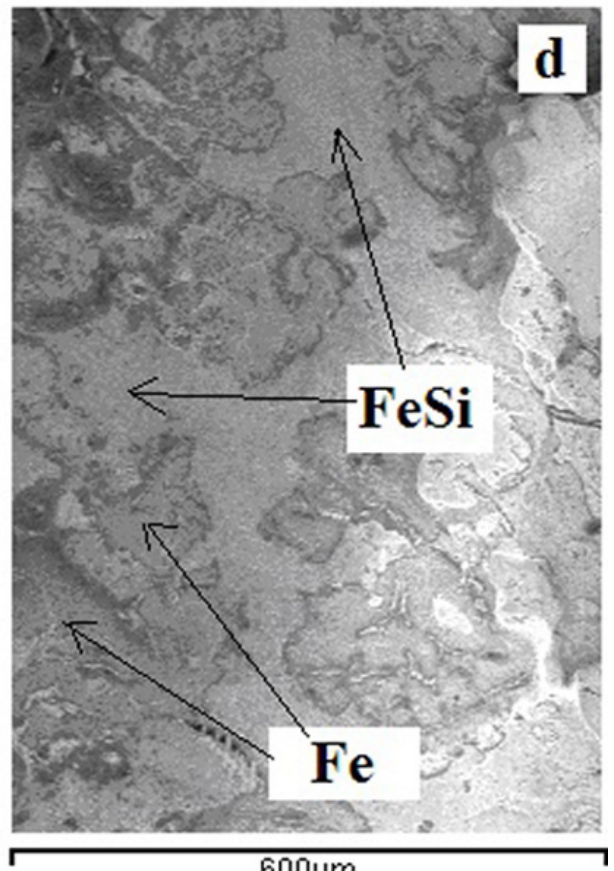

$600 \mu \mathrm{m}$

Fig. 7. SEM images and EDS analysis of high carbon ferromanganese after its dissolution, (a) three layers (A, B and C); (b) magnified image of layer A in (a); (c) magnified image of layer A in (a) before polishing; (d) magnified image of layer B

\section{Acknowledgments}

The authors are grateful for the financial support from National Natural Science Foundation of China, Project (51404001).

\section{REFERENCES}

[1] O. Grassel, L. Krüger, G. Frommeyer, L.W. Meyer, International Journal of Plasticity 16, 1391-1409 (2000).

[2] J. Lu, D. Dreisinger, T. Glück, Hydrometallurgy 141, 105-116 (2014).

[3] C. Song, Master thesis, South Centual University, Hunan, China, (2013) (in Chinese).
[4] J. Safarian, L. Kolbeinsen, INFACON XIII, Almaty, Kazakhstan. Conference proceedings 175 (2013).

[5] G. Hils, A. Newirkowez, M. Kroker, U. Grethe, R. Schmidt-Jürgensen, J. Kroos, K.H. Spitzer, Steel research international 86, 411-42 (2015).

[6] C. Tao, S. Fei, Z. Liu, J. Du, X. Fan, M. Li, Y. Chen, China's Manganese Industry 29, 1-5 (2011).

[7] A.J. Godsell, D.J. Fray, Metallurgical Transactions B 21, 217-228 (1990).

[8] B. Cartwright, S.F. Ravitz, Transactions of The Electrochemical Society 89, 373-382 (1946).

[9] F.R. Cattoir, T.A. Sullivan, Bureau of Mines, (1969).

[10] K.P.V. Lei, T.A. Sullivan, Bureau of Mines, (1971).

[11] M. Selecka, A. Salak, Powder Metallurgy Progress 9, 97-114 (2009). 